\title{
Potencialidades e limites das explicações evolutivas da cultura: um enfoque diacrônico
}

\author{
Potential and limits of \\ evolutionary explanations of \\ culture: a diachronic approach
}

Lorenzo Baravalle

Professor, Centro de Ciências Naturais e Humanas/ Universidade Federal do ABC.

Rua Arcturus, bloco Delta, sala 202

09606-070 - São Bernardo do Campo - SP - Brasil

lorenzo_baravalle@yahoo.it

Recebido para publicação em março de 2012.

Aprovado para publicação em novembro de 2012.
BARAVALLE, Lorenzo. Potencialidades e limites das explicações evolutivas da cultura: um enfoque diacrônico. História, Ciências, Saúde - Manguinhos, Rio de Janeiro, v.21, n.2, abr.-jun. 2014, p.439456.

\section{Resumo}

$\mathrm{O}$ artigo tem como objetivo a apresentação de algumas propostas relacionadas com a extensão do domínio do darwinismo ao âmbito cultural. Em particular, foi dado destaque aos modelos aqui chamados diacrônicos, que sugerem a existência de padrões de mudança cultural ao longo do tempo, conforme a teoria da seleção natural. Por meio de uma análise epistemológica de caráter mais geral, considera-se a relação entre explicação evolutiva e explicação histórica, com a finalidade de esboçar características comuns aos modelos considerados e definir sua força teórica e seus limites estruturais. Finalmente, em um plano mais especulativo, indica-se uma possível direção de pesquisa para estudos futuros.

Palavras-chave: evolução cultural; explicação diacrônica; explicação histórica; princípio-guia; parâmetros adaptativos.

\section{Abstract}

The aim of this article is to present some proposals concerning how broadly Darwinism can be applied to the realm of culture. Particular attention is paid to the models here called diachronic, which suggest the existence of patterns of cultural change over time according to the theory of natural selection. By means of a broader epistemological analysis, the relationship between an evolutionary explanation and $a$ historical explanation is considered with a view to tracing the common features of the models in question and bringing to light their relative theoretical cogency and structural limitations. Finally, and more speculatively, potential areas for future research are indicated.

Keywords: cultural evolution; diachronic explanation; historical explanation; guiding principle; adaptive parameters. 
$\mathrm{A}$ o longo dos últimos quarenta anos, o debate sobre o papel da biologia no desenvolvimento das culturas humanas tomou, em um primeiro momento, uma direção mais ou menos definida, graças aos trabalhos de caráter sociobiológico (Wilson, 1975, 1978 e, com matizes algo diferentes, Dawkins, 1976), para depois chegar a um impasse, provocado pela crítica de seus excessos (Lewontin, 1979; Sober, 1996, por exemplo). A tese principal dos primeiros sociobiologistas era a de que os comportamentos sociais do homem (partindo da agressividade e do altruísmo) deveriam ser estudados em perspectiva comparativa com os dos demais animais. Essa proposta baseava-se em dois pressupostos discutíveis. O primeiro: existem mecanismos de herança das estruturas comportamentais, determinados pelos processos de transmissão e seleção genéticas, tais que a função de comportamentos análogos, em espécies diferentes, é substancialmente a mesma; o segundo: a presença e a persistência de uma determinada classe de comportamentos se devem, quase exclusivamente, a sua adaptatividade. O primeiro pressuposto pode ser chamado de determinismo genético; o segundo, de adaptacionismo.

Mais detalhadamente, pode-se definir determinismo genético como a tese pela qual os processos seletivos atuam principalmente sobre o genótipo - o conjunto dos genes contido no cromossoma - e só indiretamente sobre o fenótipo - a soma dos traços que caracterizam um organismo. Segundo um determinista, portanto, os indivíduos são apenas uma manifestação secundária da evolução, ou seja, a realização material da "luta pela sobrevivência" entre genes que visam ocupar o mesmo lugar em uma determinada sequência cromossômica. Nessa perspectiva, os caracteres fenotípicos de um organismo são considerados adaptativos somente quando incrementam a probabilidade de transmissão da sua dotação genética (por meio da reprodução).

O adaptacionismo, por outro lado, representa - ao menos de acordo com uma certa interpretação - uma tese menos forte, de valor principalmente epistêmico. Pode ser definida como a crença no fato de que "a maioria dos caracteres fenotípicos da maioria das populações pode ser explicada por um modelo que descreve a seleção e ignora os processos não seletivos"1 (Sober, 1996, p.202), a saber, a migração entre populações e a deriva genética. Note-se que o adaptacionista não nega a existência desses fenômenos; apenas limita a relevância deles nas explicações evolutivas.

Essas teses não se implicam mutuamente e, de fato, os autores que propuseram alternativas à sociobiologia comprometeram-se, em geral, apenas com o adaptacionismo. Contudo, o determinismo genético facilita bastante a interpretação do adaptacionismo, já que explicita as condições pelas quais se deve considerar adaptativo determinado comportamento. $\mathrm{Na}$ explicação sociobiológica, a função última das organizações sociais é otimizar a difusão dos genes dos indivíduos e de seus parentes mais próximos. Agressividade e altruísmo (para citar apenas dois dos comportamentos mais comuns entre espécies) são, nessa perspectiva, simples estratégias do "gene egoísta" (Dawkins, 1976). ${ }^{2}$ Os indivíduos que difundem de modo eficaz os próprios genes são adaptados em virtude desse material transmitido, que, por sua vez, é responsável pelos comportamentos sociais bem-sucedidos, em termos de reprodução. Além da plausibilidade científica desse modelo, na sociobiologia a centralidade do gene nos processos adaptativos acaba por ser um princípio quase metafísico. O nível do gene é arbitrariamente considerado o único relevante para o entendimento dos processos seletivos (Sober, 1996, 
p.174-175), e a sobrevivência dos genes, por meio da replicação, é, às vezes, injustificadamente vista como o fim implícito da totalidade da vida orgânica.

A sociobiologia é, em muitos sentidos, inapropriada para descrever a extrema variedade dos comportamentos humanos, mas sua simples rejeição faria perder um critério que permite analisar os aspetos evolutivos da organização social humana. Se nossos comportamentos sociais não são dirigidos ao incremento da fitness (a maior difusão possível de nossos próprios genes e daqueles dos parentes mais próximos), como deveriam-se interpretar as regularidades entre diferentes sociedades do ponto de vista evolutivo?

Alguns autores, conhecidos como psicólogos evolucionistas (Tooby, Cosmides, 1992; Pinker, 1996), teorizaram a existência de mecanismos psicológicos específicos e, ao mesmo tempo, localmente variáveis (em relação aos outputs comportamentais), determinados pela seleção natural. Outros (Cavalli-Sforza, Feldman, 1981; Boyd, Richerson, 1985) sugeriram a existência de dois processos evolutivos distintos: o primeiro puramente biológico, e outro propriamente cultural (por isso, esses autores são chamados de teóricos da dupla herança). ${ }^{3}$ Este segundo tipo de processo seletivo é caracterizado por um mecanismo de herança e por parâmetros adaptativos diferentes e parcialmente independentes do primeiro. A evolução biológica devese à transmissão de material genético, considerado adaptativamente eficaz quando garante maior descendência ao indivíduo, em virtude de algum traço fenotípico característico; já o meio de transmissão da evolução cultural é a aprendizagem, e a adaptatividade de um comportamento é determinada por sua difusão na sociedade.

Embora seja difícil distinguir tais propostas em seus detalhes, poder-se-ia dizer que, em geral, os psicólogos evolucionistas se mantêm relativamente fiéis ao espírito da sociobiologia, enquanto os teóricos da dupla herança são parcialmente devedores das versões clássicas da epistemologia evolucionista (Toulmin, 1972; Popper, 1972), que pretendiam descrever os processos históricos da racionalidade ou da prática científica em termos seletivos, sem a referência ao domínio causal genético. Tanto os teóricos da dupla herança quanto os epistemólogos evolucionistas abstraem os conceitos próprios da análise seletiva e os aplicam a âmbitos da cultura humana, rejeitando, ao mesmo tempo, a relação exclusiva que esses conceitos tinham originariamente com a evolução biológica. Outra semelhança entre os dois grupos de modelos de seleção é a rejeição do determinismo genético como condição material da realização dos processos evolutivos, embora aceitem (não sempre explicitamente) o adaptacionismo como condição formal da análise do desenvolvimento das culturas - ou, mais limitadamente, da ciência.

Contudo, é importante salientar uma diferença, nem sempre claramente marcada, entre os dois tipos de enfoque. Os epistemólogos evolucionistas (com exceções como Lorenz, 1974; Ruse, 1986) normalmente demonstram pouco interesse em relacionar ontologicamente cultura e natureza. Para a maioria deles, o esquema explicativo darwinista pode ser aplicado ao desenvolvimento científico sem se explicitarem as condições biológicas concretas que o tornam possível. Os teóricos da dupla herança, diferentemente, prestam constante atenção à interação entre o nível biológico e o social, a ponto de se poder falar, mais do que de duas evoluções distintas, de uma coevolução.

Meu ponto de vista é que esses programas de pesquisa estão basicamente no caminho certo em relação a uma descrição naturalista do desenvolvimento das sociedades humanas, mas, 
para poder avançar nessa direção, precisam esclarecer uma questão fundamental: que tipo de explicação está envolvido na análise evolutiva da cultura? Dizer que a adaptatividade de um comportamento social é simplesmente determinada pela sua difusão não explica por que dado comportamento é mais difundido que outros presentes na mesma sociedade, ou seja, o que faz dele um comportamento adaptativo. Portanto, tampouco explicita as características de uma hipotética evolução cultural distinta, ao menos parcialmente, da biológica. Como observa Sober (1996, p.339), criticando a teoria de Cavalli-Sforza e Feldman (1981), que será analisada em breve: "O modelo descreve as 'consequências' do atrativo de uma ideia, não a 'causa' que a fez atrativa".

Ao longo da primeira parte do artigo consideram-se algumas questões relacionadas com esse problema e discute-se a possibilidade de ampliar o conceito (darwiniano) de evolução às dinâmicas culturais a partir de uma perspectiva histórica. O objetivo é, como em trabalhos anteriores (Baravalle, 2012a, 2012b), esclarecer de que maneira um esquema interpretativo evolucionista poderia ser plausível e útil para a compreensão das dinâmicas sociais quando considerado nos seus limites próprios. Para chegar a isso, será preciso discutir o caráter histórico da explicação evolutiva de um ponto de vista epistemológico geral e, em seguida, avaliar a viabilidade da extensão dessas conclusões à análise dos comportamentos sociais. Finalmente, darei alguma indicação geral acerca da linha de pesquisa e a estrutura que deveriam tomar os modelos evolutivos culturais para consolidar seu potencial explicativo.

\section{Explicação sincrônica e explicação diacrônica: duas interpretações da explicação evolucionista das culturas}

Primeiro, tento explicitar a observação de Sober. O fenômeno tratado por Cavalli-Sforza e Feldman (1981) é a baixa natalidade característica das sociedades da Europa ocidental a partir de finais do século XIX. Ter menos filhos é um traço evidentemente negativo para a fitness, isto é, "estendeu-se 'apesar' de sua eficácia biológica, não 'por causa' dela" (Sober, 1996, p.336). A hipótese dos autores é a de que apareceu um caráter ("ter dois filhos") que entrou em competição com o mais difundido até aquele momento ("ter cinco filhos") e, devido a um processo de transmissão horizontal - sobretudo linguística, no âmbito da mesma geração -, o primeiro acabou saindo vencedor. A possibilidade de que um comportamento surgido culturalmente - através da aprendizagem - compita com outro que é derivado biologicamente é determinada, segundo Cavalli-Sforza e Feldman, pelo "atrativo psicológico" do primeiro. Em outras palavras, a emergência de uma evolução cultural distinta de (e em contraste com) a evolução biológica dependeria de circunstâncias nas quais os membros de uma sociedade se veem afetados pela presença de estímulos comportamentais fortes, funcionalmente irredutíveis às exigências biológicas.

O modelo de Cavalli-Sforza e Feldman (1981) é criticado por Sober (1996) por não explicar em detalhes o aspecto psicológico da transmissão cultural, ou seja, as características que tornam um comportamento social atrativo. A teoria de Richerson e Boyd (2005; Boyd, Richerson, 1985) representa, nesse sentido, um avanço, já que explicita, com inspiração na psicologia evolucionista e particularmente em Tooby e Cosmides (1992), três propriedades, em princípio quantificáveis, que determinam a probabilidade de difusão de um comportamento aprendido: 
simplicidade cognitiva (conteúdo), difusão prévia (frequência) e status dos agentes (modelo) (Richerson, Boyd, 2005, p.96). Essas características, que determinam o que Richerson e Boyd chamam de transmissão preferencial e que definem os processos de transmissão horizontal, poderiam satisfazer parcialmente à pergunta sobre as causas da difusão de comportamentos não biologicamente eficazes, mas não esgotariam a questão. Embora Richerson e Boyd descrevam as causas psicológicas da difusão de comportamentos potencialmente mal adaptativos, caso se limitassem a isso dificilmente conseguiriam explicar o processo evolutivo que levou a tal comportamento a partir de outro cultural, isto é, a mudança cultural.

A afirmação de Sober (1996) citada anteriormente pode ser lida em dois sentidos. Em um primeiro, que se pode chamar de sincrônico, ou referente às causas próximas (Mayr, 1961, 1982), a difusão dos comportamentos que não incrementam a fitness pode ser entendida em termos de preferências psicológicas, individuais, as quais impulsionam os membros de uma sociedade à imitação de modelos atrativos em um determinado momento. Essa interpretação não explicita as condições específicas da evolução cultural, mas tão somente os parâmetros que definem os indivíduos como mais ou menos culturalmente "adequados" em uma sociedade. ${ }^{4}$

A principal característica da adequação social, segundo Richerson e Boyd (2005, p.166-170), é o "conformismo". Ao longo de sua obra, os autores elaboram uma análise antropológica, mostrando como os membros incapazes de se adequar aos comportamentos mais comuns da comunidade - considerados, conforme sua função própria, como "variantes culturais" são prejudicados no desenvolvimento de suas atividades. Mas essa "incapacidade" social, em muitos casos, implica uma inadequação biológica, ou seja, uma maior dificuldade em encontrar um casal para reproduzir-se. A proposta de Richerson e Boyd diferencia-se então da sociobiologia, já que define um sistema de causas propriamente psicológicas na base dos comportamentos sociais, embora os parâmetros adaptativos naturais ainda solapem os culturais, ao menos no que concerne à eficácia a longo prazo.

O incremento da fitness é, em minha opinião, simplesmente mediado pela difusão de comportamentos não imediatamente adaptativos, que, apesar de gozarem de uma boa difusão, não constituem uma real alternativa evolutiva à reprodução biológica.

Em outro sentido, chamado de diacrônico, ou referente às causas remotas, a explicação requerida tem a ver com as condições pelas quais determinados comportamentos se desenvolveram em um dado momento e substituíram, mais ou menos gradualmente, os anteriores. As fases de uma hipotética evolução cultural, entendida dessa maneira, não são descritíveis apenas em termos psicológicos. Dada a substancial invariabilidade de nossas faculdades mentais - para Richerson e Boyd (2005, p.181), biologicamente estáveis a partir do Pleistoceno -, a difusão de um novo comportamento não adaptativo, do ponto de vista do indivíduo, depende de seu atrativo "local": a escolha pessoal é limitada aos comportamentos que apresentam características preferenciais (conteúdo, frequência, modelo) em um determinado momento (da vida do indivíduo).

Mas Richerson e Boyd (2005, p.158) afirmam também existirem processos cumulativos, e que "muitos tipos de comportamento admitem melhoras sucessivas até algum estado ótimo". Para que isso seja possível, é preciso que existam processos relevantes em escala populacional e temporalmente extensa. Os autores consideram, nesse sentido, que a evolução das variantes culturais (e, em particular, das técnicas) poderia ser efeito da seleção natural aplicada às 
dinâmicas sociais (p.109). Essa ideia é particularmente interessante, uma vez que amplia o conceito de pressão seletiva a comportamentos coletivos e reabilita a noção de seleção de grupo, geralmente rejeitada pelos sociobiologistas.

Estudos nesse sentido também foram realizados por Hull (1980), que introduziu o conceito de interatuante coletivo e Sober e Wilson (1998; Wilson, Sober, 1994), que desenvolveram um modelo compatível com esse conceito para descrever características fenotípicas que podem ser compartilhadas por mais indivíduos.

Em síntese, para Richerson e Boyd (2005) existem dois mecanismos na base da evolução cultural: o primeiro, a transmissão preferencial (causa próxima), determina a possibilidade, por parte dos indivíduos, de escolher comportamentos não diretamente relacionados com o incremento da fitness; o segundo, a seleção natural aplicada às dinâmicas sociais (causa remota), define a persistência - sobrevivência, em outras palavras - e a otimização de alguns comportamentos ao longo do tempo, em um contexto populacional e de maneira diferencial.

Mas o que torna um comportamento culturalmente ótimo? Os autores respondem de forma ambígua. Por um lado, a transmissão preferencial desenvolve comportamentos ótimos pela sobrevivência individual, mediada pela adequação dos membros às variantes culturais mais comuns na própria sociedade, de modo que a evolução cultural não seria nada mais que a extensão da evolução biológica. Por outro lado, Richerson e Boyd (2005) parecem sugerir que a transmissão preferencial favorece, por meio das pressões seletivas nos contextos sociais, a otimização de certos comportamentos cujos objetivos são intrinsecamente culturais, embora não especifiquem quais. Na prática, tentam mediar essas duas interpretações, recorrendo ao conceito de coevolução. A proposta é considerar os limites biológicos (as necessidades reprodutoras) como vinculantes pela evolução das variantes culturais, as quais, por sua vez, também têm efeitos relevantes sobre as possibilidades de difusão de nossos genes (essencialmente, por meio do condicionamento de nossos hábitos sexuais).

Esse compromisso privilegia, ainda, em minha opinião, a componente sociobiológica, e não ajuda a compreender a possibilidade de uma evolução propriamente cultural. Para superar essa dificuldade, sugiro concentrar a atenção sobre a explicação diacrônica da evolução cultural, já que, seguindo o modelo de Richerson e Boyd (2005), a seleção natural aplicada às dinâmicas sociais parece mais promissora para delinear uma real alternativa à explicação adaptacionista clássica no âmbito social.

Ao propor uma explicação diacrônica, a intenção é, em primeiro lugar, dar um enfoque metodologicamente independente das causas próximas, tanto as biológicas quanto as psicológicas. Se os comportamentos sociais exibem características evolutivas, conforme os estudos de Cavalli-Sforza e Feldman (1981) e de Richerson e Boyd (2005) sugerem, e são "visíveis" a pressões seletivas, isso significa que, em princípio, deve ser possível descrever seus processos próprios sem invocar suas bases materiais, da mesma maneira que uma análise psicológica dotada de ferramentas teóricas autônomas não é impedida pela suposta dependência dos estados mentais em relação aos cerebrais. Essa escolha metodológica não significa, em absoluto, a irrelevância da biologia, que determina o horizonte das possibilidades comportamentais, nem das intenções nas escolhas sociais. O que aqui se propõe é colocar entre parênteses o aspecto psicológico, por acreditar que seu papel seja importante somente do ponto de vista sincrônico, que não será adotado aqui. As intenções são individuais, temporalmente 
determinadas e privadas. Um estudo evolutivo diacrônico só pode aceder a comportamentos, por meio da comparação entre funções atuais e ancestrais, ou a documentos, tanto no caso da cultura quanto no da natureza. Nesse segundo âmbito, a análise dos documentos pode ser equiparada à análise dos registros fósseis. Sem negar a presença de causas endógenas, a análise evolucionista deve privilegiar as causas exógenas, entendidas como limites e desafios implícitos no ambiente natural e no social. Assim, o caso da baixa natalidade, por exemplo, poderia ser explicado por meio de um modelo que elucide os problemas propriamente sociais, cuja solução é facilitada por uma família restringida. ${ }^{5}$

Empreender essa linha de pesquisa implica, em segundo lugar, adotar uma perspectiva propriamente histórica da evolução, tanto biológica quanto humana. Em outras palavras, quando realizável, o objetivo de uma explicação diacrônica da evolução cultural seria o de mostrar a existência de regularidades nomológicas relevantes, capazes de explicar as mudanças sociais reais, usando como teorias de referência, além do darwinismo, a ecologia, a economia e a sociologia. Isso não equivale de modo algum a reviver algum tipo de darwinismo social, nem pressupõe a existência de "leis históricas" propriamente ditas. O objetivo não é reduzir o desenvolvimento das culturas humanas a um processo histórico (pre)determinado, mas investigar a possibilidade de que existam pressões seletivas que atuam, em um sentido relevante e além das restrições biológicas, sobre nossas escolhas sociais a longo prazo.

Na verdade, não se trata de um projeto novo. Em certo sentido, o antropólogo estadunidense Marvin Harris (1977, 1979), por exemplo, propôs, com seu materialismo cultural, um programa parecido. Baseando-se em uma leitura crítica de Marx, Harris emprega um modelo interpretativo dos fenômenos sociais em que as regularidades relevantes para a explicação da mudança cultural são materiais - ou seja, relacionadas com a resolução de problemas práticos -, mas não apenas biológicas. A ideia central do materialismo cultural é a de que ele "se interessa pelo problema de compreender a relação entre as partes dos sistemas socioculturais e pela evolução dessas relações, partes e sistemas" (Harris, 1979, p.63). Harris abre mão das implicações políticas do marxismo, mantendo as categorias de infraestrutura, estrutura e superestrutura apenas como instrumentos teóricos para a localização de invariantes culturais tais como as tecnologias para a manutenção do tamanho de uma população, as modalidades de interação com o ambiente e de abastecimento de recursos. Essas invariantes culturais (próprias do nível infraestrutural) servem de base fixa para a variabilidade espaçotemporal das sociedades reais e determinam não somente os modos de reprodução (genuinamente biológicos), mas também os modos de produção (principalmente culturais), que regulam as possibilidades evolutivas das instituições (estrutura) e das estratégias cognitivas das populações (arte, religião e, até, a ciência: a superestrutura).

O trabalho de Harris (1979) está intimamente relacionado com a presente proposta, porque evidencia a possibilidade de considerar naturalisticamente a variação cultural, sem se comprometer com o determinismo genético dos sociobiologistas. Obviamente, aqui a teoria de referência é o darwinismo e não o marxismo, embora, como implicitamente mostrado pelos teóricos da dupla herança, sua aplicação ao domínio cultural não possa ser rígida. ${ }^{6}$ Como no caso do marxismo crítico de Harris, a aplicação do adaptacionismo à evolução cultural implica uma deformação de suas teses próprias e, em última instância, poderia levar a um modelo autônomo - o que provavelmente seria desejável. 


\section{Explicação evolutiva e explicação histórica}

Para expor mais claramente essa aproximação entre explicação histórica e evolutiva, seu potencial e seus limites, farei uso do ponto de vista de Fodor e Piattelli-Palmarini (2010). Porém, como os autores negam qualquer conteúdo científico ao conceito de seleção, a apresentação de suas ideias será dialética, caracterizada pela intenção de ir além de suas posições antidarwinistas. Em relação à inadequação teórica do projeto adaptacionista, Fodor e Piattelli-Palmarini (2010, p.181) afirmam:

Pensamos que, efetivamente, existam algumas explicações adaptacionistas genuínas e que sejam exatamente o que parecem ser superficialmente: são explicações 'históricas'. ... as explicações históricas oferecem (não leis, mas) narrações plausíveis; narrações que pretendem articular a cadeia causal dos eventos que leva ao evento a explicar. As explicações nomológicas têm a ver com relações (metafisicamente necessárias) entre propriedades; as narrações históricas têm a ver com relações (causais) entre eventos.

Em outras palavras, os autores consideram, em primeiro lugar, que a única interpretação plausível da teoria darwinista é sua identificação com a história natural, e sustentam, consequentemente, que isso a esvazia de qualquer conteúdo explicativo profundo. Minha opinião é que se deve matizar a primeira afirmação e rejeitar a segunda.

Cabe dizer que nenhuma das duas teses é nova. A interpretação da teoria da seleção natural como teoria genuinamente histórica está presente em vários darwinistas de primeira hora, como Huxley (1880, p.214), que considera que a lei da evolução das formas orgânicas deveria ser "a lei de ordem invariável da grande cadeia de causas e efeitos da qual todas as formas orgânicas, antigas e modernas, constituem os elos", ou seja, uma lei sobre o desenvolvimento real das formas de vida no nosso planeta. Já Popper (1957) acredita ser impossível fornecer leis históricas. Para ele, a substancial unidade (e unicidade) do processo evolutivo não permitiria generalizações nomológicas, ${ }^{7}$ já que as leis universais supostamente derivadas da observação de um único fenômeno não são testáveis, mas apenas a definição de "tendências". ${ }^{8}$ É precisamente uma concepção desse tipo, a meu ver, a que fundamenta o preconceito segundo o qual as explicações históricas seriam meras narrações elaboradas post hoc, incapazes de universalidade e de gerar previsões, como creem Fodor e Piattelli-Palmarini (2010, p.183). Contudo, como antecipei, o objetivo das explicações diacrônicas, tanto as biológicas quanto as culturais, não é subsumir eventos a leis históricas, cuja efetiva ausência autorizaria o pessimismo epistemológico de Fodor e Piattelli-Palmarini. Mais modestamente, o que pretendem de fato é considerar como os acontecimentos históricos (naturais ou humanos) oferecem justificação empírica para acreditar em regularidades seletivas, que, como será visto, não podem ser consideradas leis históricas no sentido de Popper.

Para sustentar a analogia entre explicação evolutiva e explicação histórica, e assim articular sua crítica, os autores usam o seguinte exemplo: “Napoleão foi derrotado em Waterloo porque chovia há dias e o solo era demasiado lamacento para a carga da cavalaria. ... Mas disso não se segue que existam leis que conectem a quantidade de lama no solo com o êxito das batalhas" (Fodor, Piattelli-Palmarini, 2010, p.182). ${ }^{9}$ E acrescentam que, na biologia evolutiva, acontece algo parecido e ao mesmo tempo diferente. A saber: a evolução de um traço é explicada pelos neodarwinistas por meio de uma história causal plausível, mas a partir daí se pretende 
que a "narração" dê apoio à teoria da seleção natural, considerada modelo para explicar a mudança. Contudo, para Fodor e Piattelli-Palmarini, essa teoria não proporciona leis de cobertura pertinentes para determinar propriedades universais de fenômenos históricos como as supostas adaptações diferenciais. Às vezes, é mais adaptativo ser pequeno outras, ser grande; em determinadas ocasiões, é melhor ter asas, em outras, escamas; em certos ambientes, é preferível ser carnívoro, em outros, herbívoro etc.

Para Fodor e Piattelli-Palmarini (2010), não há, na teoria da seleção natural, leis que conectem esses caracteres particulares com os respectivos ambientes em que eles aparecem, senão no sentido genérico, já que, historicamente, encontram-se vagas correlações entre determinados traços e ambientes. Falar de uma genérica adaptação ao ambiente, nessa perspectiva, seria trivial, já que a expressão não denota qualquer processo causal genuíno, mas somente o fato de que há animais com determinados nichos e não outros. Cada um dos caracteres considerados tem causas endógenas morfogenéticas ${ }^{10}$ - os autores dedicam toda a primeira metade de seu livro a enumerá-las - independentes das supostas causas seletivas e, dado que essas causas expressam regularidades nomológicas genuínas (referentes ao domínio da física, da bioquímica ou, em geral, aos mecanismos de desenvolvimento filogenético dos embriões), devem ser preferidas, na explicação científica, a estas, que apresentam apenas uma sequência de efeitos. Eis aqui a ideia de que só as explicações sincrônicas (referentes a causas próximas, nesse caso consideradas endógenas) subsomem eventos a leis, enquanto as diacrônicas seriam incapazes de fazê-lo.

A tese de que as explicações históricas não subsomem genuinamente eventos a leis é, no mínimo, discutível. É evidente que não se trata do sentido sugerido pelo exemplo de Napoleão. Porém, seria errado pensar que a pesquisa histórica não emprega enunciados universais. Como nota Nagel (1961) entre outros (Hempel, 2005), talvez seja verdade que o historiador não "estabelece" leis da mudança histórica qua historiador, mas isso não implica que não afirme enunciados singulares que exemplificam leis da psicologia ou da sociologia, assim como faz o geólogo, que "trata de determinar, por exemplo, a ordem sucessiva das formações geológicas, aplicando diversas leis físicas a seu material de estudo" (Nagel, 1961, p.713). A questão importante, portanto, não seria a existência ou não leis de cobertura - ou seja, capazes de subsumir os fenômenos -, exemplificadas pela explicação histórica, mas se as leis "tomadas emprestadas" de outras disciplinas são relevantes para a explicação em questão. Infelizmente, Fodor e Piattelli-Palmarini (2010, p.188) não parecem impressionados por esse tipo de considerações, já que nem o geólogo, para eles, estaria subsumindo eventos a leis no sentido requerido.

Mas isso parece advir de uma profunda confusão entre elementos diferentes das teorias científicas, a saber, a formulação de leis, a enunciação de hipóteses históricas e a explicação de eventos particulares. ${ }^{11}$ Sober (1996, p.45) observa que:

Para decidir se algo é uma lei ou uma hipótese histórica, deve ser claro que 'proposição' se deseja classificar. Por exemplo, perguntar se 'a seleção natural' é uma lei carece de sentido até que se especifique de que proposição relativa à seleção natural se está falando. Dizer que a seleção natural é a responsável pelo fato de que os seres humanos tenham o polegar oponível é enunciar uma hipótese histórica; mas dizer que a seleção natural 
levará a produzir uma proporção igual de gêneros nas circunstâncias descritas por Fisher é formular uma lei.

Em primeiro lugar, é importante observar como a explicação evolucionista não fornece simplesmente uma "narração" que exemplifica leis "emprestadas" por outras teorias; ela é parcialmente autônoma, ou seja, proporciona também "internamente" leis que subsomem os eventos históricos naturais. Mas o essencial é que essas leis próprias da teoria da seleção natural (como a da proporção de gêneros de Fisher, que prevê, dadas certas condições iniciais, o desenvolvimento da proporção entre machos e fêmeas em uma relação um para um) não são redutíveis a hipóteses históricas isoladas, que por si só - é verdade - careceriam de caráter nomológico. As leis, ao contrário, proporcionam as regularidades nomológicas que permitem formular tais hipóteses e integrar, de maneira cientificamente relevante, diferentes eventos (como demonstra a aplicação do citado modelo de Fisher, ceteris paribus, a distintas populações).

Pouco importa se a explicação desses fenômenos é sincrônica ou diacrônica, se faz referência a causas próximas ou remotas, endógenas ou exógenas. O fato histórico (como qualquer outro) não é imediatamente subsumido a uma lei, mas a hipótese que tenta explicá-lo pode sê-lo (embora nem sempre o seja).

Além de não serem redutíveis a hipóteses históricas, como parecem acreditar Fodor e Piattelli-Palmarini, as leis da seleção tampouco são leis históricas, no sentido popperiano, já que não pretendem explicar o inteiro processo evolutivo, mas, simplesmente, os eventos que acontecem durante o processo. A "universalidade" da teoria darwiniana provém da aplicabilidade das leis formuladas, caso verdadeiras, a todas as populações de organismos vivos, e não do fato de que pretende descrever nomologicamente o desenvolvimento das formas de vida reais como um todo. ${ }^{12}$

Considere-se agora o ponto central: afirmar que a explicação histórica nada mais é que uma narração vazia porque faltam leis que conectem a quantidade de lama e o êxito das batalhas, ou leis que conectem os polegares oponíveis com um determinado ambiente, equivale a afirmar, por exemplo, que certo modelo da psicologia é incompleto porque faltam leis que correlacionem a personalidade com as preferências gastronômicas. O problema não é a falta de leis desse tipo (obviamente absurdas), mas que seja pertinente escolher leis "universais" (não referentes diretamente a objetos particulares) que fundamentem a explicação dos eventos singulares por meio de hipóteses oportunas.

Diez e Lorenzano (2013, p.1159) observam, ademais, que todos os modelos explicativos darwinianos (sobre, por exemplo, proporção dos gêneros, estratégias de acasalamento, técnicas de aquisição de comida etc.), e as leis neles formuladas podem ser unificados sob um "princípio-guia" do seguinte tipo: "Princípio-guia da seleção natural (PGSN)': quando um caráter muda em uma população, busca sua força adaptativa, isto é, alguma função ou comportamento que, em um ambiente dado, incrementa o sucesso reprodutivo (a saber, a fitness) melhor do que se o caráter fosse ausente". Quando coerentes com esse princípio, as hipóteses históricas particulares adquirem valor explicativo no quadro da teoria darwiniana, por meio do recurso a leis específicas que, aplicadas aos casos particulares, dão conta dos aspectos locais dos processos adaptativos (como a variação do tamanho, a aparição de asas ou escamas, o desenvolvimento de determinados hábitos alimentares etc.). 
Será possível ampliar esse principio à mudança cultural para dar unidade aos modelos apresentados? Na primeira parte do artigo mostrou-se que a especificidade dos processos de transmissão cultural é serem, muitas vezes, não adaptativos, ou, até, mal-adaptativos. Também sugeri que considerar diacronicamente a mudança cultural implica tomar certa distância das posições sociobiológicas e dos parâmetros adaptativos biológicos. Assim, depara-se, na verdade, com um princípio-guia bastante diferente do da teoria da seleção natural clássica. Esse princípio poderia ser enunciado da seguinte maneira: "'Princípio-guia da evolução cultural (PGEC)': quando um comportamento muda em uma população, busca sua força adaptativa, isto é, alguma função que, em um ambiente social dado, incrementa $x$ melhor do que se o comportamento fosse ausente".

Esse princípio é meramente heurístico, já que não especifica as condições gerais pelas quais se deveria considerar adaptado um comportamento cultural. Note-se que essa formulação não exclui que existam comportamentos adaptativos no sentido enunciado pelo PGSN, conforme uma análise adaptacionista clássica. Mas obviamente são menos interessantes para o ponto de nossa análise, dado que são explicáveis por meio de hipóteses sociobiológicas. A falta de um princípio-guia determinado gera problemas na hora de definir uma unidade teórica entre modelos, mas não invalida a primeira parte de nossa argumentação, uma vez que também as explicações evolutivas culturais, assim como as naturais, podem contar com leis - ou ao menos "esquemas de leis" (Brandon, 1978) - não redutíveis a hipóteses históricas. É o caso, por exemplo, do modelo da mudança linguística de Cavalli-Sforza (1996), no qual a variação da morfologia das palavras é considerada conforme os padrões da evolução genética, ou do modelo dos mecanismos de transmissão cultural entre gerações, em Boyd e Richerson (1985; Richerson, Boyd, 2005), que considerarei com mais detalhe na última seção.

Não se trata aqui de afirmar que esses modelos sejam conclusivamente apoiados por dados empíricos. Qualquer modelo é falível desse ponto de vista. A questão é que eles refletem a estrutura explicativa aqui apresentada: não são teorias "sobre" a história - como as criticadas por Popper - nem simplesmente interpretações evolutivas de eventos históricos isolados. Esses modelos aplicam leis, próprias do domínio da biologia, da economia e da sociologia, a populações específicas, permitindo avançar hipóteses sobre a difusão de determinados comportamentos sociais, "dizendo como os sistemas do tipo especificado se desenvolvem no tempo e governando, assim, as trajetórias das populações, ao descreverem a probabilidade dos estados que o sistema poderia ocupar em alguma quantidade determinada de tempo posterior" (Lorenzano, 2011, p.64).

Deveria agora ficar mais claro que a diferença entre as explicações históricas naturais e as humanas, característica da qual depende o enquadramento das explicações históricas humanas na teoria darwiniana, não reside no fato de que as duas exemplificam regularidades nomológicas de maneiras distintas. A diferença é que apenas as naturais possuem um princípioguia definido para determinar o caráter comum de todos os fenômenos considerados. Esse princípio, negado por Fodor e Piattelli-Palmarini (que, como visto, desconsideram o fato de que caracteres diferenciais como tamanho ou costumes alimentares possuem propriedades comuns, nomologicamente relevantes), é, na verdade, aceito por qualquer biólogo evolucionista: trata-se da tendência à difusão de traços que incrementam a fitness biológica (Diez, Lorenzano, 2013). 
O princípio-guia é muito importante para determinar a relevância das leis implicadas na explicação e para a unificação dessas leis em uma única teoria. Na ausência dele - nisso Fodor e Piattelli-Palmarini (2010) têm razão - não é possível considerar as várias hipóteses evolutivas culturais (acerca do desenvolvimento de um comportamento social, de uma técnica ou de uma teoria) no quadro de uma teoria completa. Contudo, isso não significa que a explicação evolutiva cultural seja um mero truísmo, a saber, a explicitação da ideia de que há classes de comportamentos nas sociedades que variam e progridem. Assim como em outras ciências históricas (a geologia, por exemplo) o uso de leis derivadas de outras teorias fundamenta nomologicamente a explicação e permite, em certa medida, a previsão. Além disso, a formulação de um princípio-guia heurístico, o PGEC, não deve ser considerada um limite, mas um incentivo para a pesquisa nesse âmbito.

\section{Estrutura, limites e vantagens da explicação evolutiva diacrônica das culturas}

Tendo em conta as limitações consideradas anteriormente, tentarei mostrar, nesta última parte do artigo, qual poderia ser a estrutura da explicação evolutiva diacrônica dos comportamentos culturais. Como discutido na seção anterior, a aproximação entre a explicação histórica e a evolutiva não é tão negativa do ponto de vista científico quanto pensam alguns. Uma análise histórica baseada nas dinâmicas da seleção natural pode descrever propriedades reais dos sistemas culturais. Além disso, aceitando uma instância provisória do que deveria ser o princípio-guia das mudanças culturais, será talvez possível, no futuro, ter uma teoria geral acerca desses fenômenos. Os críticos desses programas de pesquisa esquecem que, muitas vezes, para poder chegar a uma teoria desse tipo, é indispensável formular hipóteses incompletas e dificilmente contrastáveis.

Como visto, na classe de modelos considerada, a escolha dos casos de estudo é determinada principalmente pela não adaptatividade biológica de um fenômeno cultural ou por sua maladaptatividade, como no caso da baixa natalidade. Isso sugere que as pressões seletivas estejam agindo em outro nível que não aquele da otimização da fitness individual. Essa hipótese, que tem apoio na ideia de que existe algo tal como interatuantes coletivos (Hull, 1980), visíveis à seleção além dos indivíduos, justificaria a análise de características populacionais complexas como traços comportamentais individuais. Nesse sentido, e adotando a formulação de Richerson e Boyd (2005), pode-se dizer que os comportamentos humanos são analisáveis em termos de variantes culturais, ou seja, conforme a função comum que tais comportamentos desenvolvem na sociedade. ${ }^{13}$

Uma variante cultural pode ser considerada um conjunto de informações comportamentais. Desse ponto de vista, sua difusão depende sobretudo de seu atrativo local, estudado pela perspectiva sincrônica, normalmente adotada pelos psicólogos evolucionistas. Mas, ao mesmo tempo, as variantes culturais são unidades evolutivas, uma vez que o sucesso ou o insucesso na realização de uma função por parte de um comportamento social determina o grau de mutação e as probabilidades de transmissão da variante correspondente na geração seguinte.

O que interessa aos modelos evolucionistas, em uma perspectiva diacrônica, é esse aspecto histórico. A pergunta que dirige a análise diacrônica é análoga à que o naturalista se põe quando compara um organismo com um antepassado fóssil: por que determinados caracteres 
(como o tamanho ou a presença de asas etc.) têm aparecido ou mudado? Mais exatamente no nosso caso: por que, em um determinado contexto social, torna-se mais comum do que anteriormente ter menos filhos ou agir conforme um determinado modelo econômico, ou ainda atribuir autoridade a uma instituição etc., ou seja, ir de encontro à otimização da fitness biológica ou a outros comportamentos culturais generalizados?

Além dos mencionados trabalhos de Harris, Boyd e Richerson, e Cavalli-Sforza e Feldman, os quais fornecem modelos mais articulados dessas mudanças e formulam leis para interpretá-las, vários outros estudos oferecem hipóteses históricas concretas. É o caso das análises etnológicas de Blake (1989) sobre o tamanho da família em comparação com os resultados intelectuais e culturais, as pesquisas antropológicas de Knauft (1985) e Stark (2003) sobre o papel mal-adaptativo das superstições (cujas implicações são desenvolvidas em detalhe em Baravalle, 2011) e os modelos estatísticos de Salamon (1992) sobre a migração entre mundo rural e metrópole. Nem todos esses autores apoiam diretamente um modelo evolucionista em particular. Porém, todos os seus trabalhos apontam para a presença, em determinados momentos históricos, de variantes culturais mais ou menos definidas no detalhe (taxas de natalidade e de escolaridade, leis discriminatórias, preferências profissionais etc.), em conflito com outras, que se difundem diferencialmente e mudam em função da sustentabilidade - daqui a pouco mostrarei em que sentido - dos comportamentos associados. Da mesma maneira são interpretáveis os processos de aperfeiçoamento das técnicas (Needham, 1979, sobre a bússola; McBrearty, Brooks, 2000, sobre a fabricação de artefatos pré-históricos) e de difusão de bens de consumo e de ideias científicas e religiosas (Toulmin, 1972; Dennett, 1995, 2006).

Poder-se-ia dizer que a diferença entre a explicação do naturalista e a do evolucionista cultural é que a primeira, além de elaborar modelos sobre a mutação, a variabilidade e a herança, pode invocar a adaptatividade como princípio explicativo global, enquanto à segunda falta um critério desse tipo. É possível mostrar isso com um exemplo. Imaginemos uma população cuja proporção entre machos e fêmeas é de um para um. Isso pode ser explicado pela lei da proporção dos gêneros de Fisher, e pode-se acrescentar, por PGSN, que os membros do grupo que contribuem para manter essa proporção são mais adaptados, já que sua descendência terá mais possibilidade de se reproduzir. Consideremos agora uma população humana cuja proporção é de dois para um a favor das fêmeas. Um modelo sobre a evolução cultural pode explicar esse fato por meio de leis estatísticas que indiquem como, em determinadas sociedades poligâmicas, a tendência da composição de gêneros evolui em direção a essa proporção. Porém, não se poderá inferir que o fenômeno tenha valor adaptativo, nem no sentido biológico, uma vez que essa proporção poderia ter uma função distinta à de incrementar a fitness individual, nem em outro sentido qualquer (por que - e para que fim - ela deveria ser considerada mais vantajosa do que a de três para um, por exemplo?). A primeira seria uma explicação genuinamente darwinista, enquanto a segunda, no máximo, uma explicação histórica baseada em algumas regularidades nomológicas próprias da teoria evolutiva.

Contudo, comparando vários estudos (Toulmin, 1972; Cavalli-Sforza, 1996, ambos sobre a linguagem; Harris, 1985, sobre as proibições alimentares; Lorenz, 1974, sobre os mecanismos de aprendizagem; Cavalli-Sforza, Feldman, 1981; Richerson e Boyd, 2005, sobre a variação demográfica), é possível individuar outro pressuposto mais ou menos comum nesse tipo de 
modelo, além dos já considerados. Em minha opinião, a premissa implícita das explicações diacrônicas é, parafraseando Harris (1979, p.70-72), que as variantes culturais não definem simplesmente, como sustentam os sociobiologistas, adaptações biológicas complexas, isto é, conjuntos de comportamentos dirigidos ao incremento da "reprodução", mas, sobretudo, estratégias de otimização da "produção".

As técnicas de produção, consideradas comportamentos direta ou indiretamente dirigidos à multiplicação dos recursos materiais, representam "a principal zona interfacial entre natureza e cultura", que, embora historicamente dependente das preferências humanas, "vê-se afetada por leis físicas, químicas, biológicas e ecológicas" (Harris, 1979, p.73). Assim, sem negar a autonomia individual da escolha social, a difusão das variantes culturais dependeria de pressões evolutivas naturais que, ao longo das gerações, limitam os comportamentos com funções produtivamente inadequadas e solapam os mecanismos da adaptação puramente biológica por meio de um mecanismo análogo.

É nesse sentido que falei de "sustentabilidade" dos comportamentos sociais em relação às variantes culturais. As estratégias produtivas determinam um domínio de comportamento que influencia profundamente nossas possibilidades de sobrevivência e, ao mesmo tempo, ao longo do desenvolvimento humano, tem se tornado independente de certos limites ambientais. Mas os produtos dessas estratégias não se colocam fora do espaço biológico e, portanto, também sofrem as pressões seletivas que regulam esse espaço. A modificação do ambiente limita as tendências reprodutivas e é limitada por elas, desenvolvendo o que se poderia considerar uma coevolução entre populações e nichos. A sustentabilidade, nessa perspectiva, seria, portanto, uma característica adaptativa de alto nível, que denota equilíbrio entre reprodução e produção.

Uma análise em múltiplos níveis adaptativos é considerada indispensável por muitos autores (Wilson, Sober, 1994; Boyd, Richerson, 1985; Wynne-Edwards, 1962), para dar conta dos comportamentos das coletividades (Baravalle, 2012a). No caso das comunidades humanas, alguns traços sociais cuja explicação biológica é tradicionalmente complexa, como o altruísmo, parecem ser mais facilmente analisáveis em termos de vantagem produtiva e sustentabilidade (Harris, 1979). Em apoio a essa tese, vale a pena citar Mayr (1982, p.75), que observa: "a complexidade estruturada dos organismos viventes é organizada hierarquicamente e os níveis superiores da hierarquia são caracterizados pela emergência de novidades". Na mesma linha, Dobzhansky (1983, p.396) conclui: "considerando a evolução do mundo vivente no seu conjunto ... não se pode evitar o reconhecimento de que aconteceu um progresso, ou um avanço, ou um crescimento, ou um enobrecimento".

De acordo com essas sugestões, não parece assim tão improvável que as pressões seletivas influam sobre características gerais das populações, ou até determinem características adaptativas "novas". O que permitiria definir, com certo grau de plausibilidade, a otimização da produção como critério próprio de seleção das variantes culturais seria, portanto, além de ela ser uma característica compartilhada por uma extrema variedade de comportamentos humanos, o fato de que sua "novidade" evolutiva não está em contraste com nossas intuições sobre a natureza dos processos seletivos. 


\section{Considerações finais}

De um ponto de vista puramente metodológico, Sterelny e Kitcher (1988) sustentam que a aplicação dos instrumentos analíticos da teoria da seleção natural, em relação aos diferentes níveis de organização do mundo vivente, deveria ter um caráter "convencionalista", já que, de fato, não existe uma única maneira de representar os processos seletivos nem seus objetivos. Nessa perspectiva, a ideia de que as dinâmicas de otimização da produção, como consequência de mecanismos de seleção em múltiplos níveis, constituam um mecanismo importante nos processos de evolução cultural parece ser, se não comprovada, pelo menos fecunda. Ela pode ser exemplificada no "'Princípio-guia da evolução cultural provisório (PGECp)': quando um comportamento muda em uma população, busca sua força adaptativa, isto é, alguma função que, em um ambiente social dado, incrementa 'a produtividade da população' melhor do que se o comportamento fosse ausente". Talvez o PGSCp não represente um princípio-guia no sentido de Diez e Lorenzano, já que não define um parâmetro adaptativo comprovável ou medível no atual estado da pesquisa. Mas essa limitação não tira o valor heurístico do pressuposto, o qual, conjuntamente com PGSC, pode ser considerado um bom fundamento epistemológico para a análise evolutiva dos comportamentos sociais. O princípio é "provisório", já que não há ainda elementos suficientes nem evidência empírica para afirmar sua validade no contexto de uma teoria unificada da mudança cultural. Contudo, como mostrei, a atual falta de uma teoria desse tipo não implica que as explicações diacrônicas não possuam valor científico próprio. Qualquer crítica a priori, à la Fodor, dos modelos diacrônicos deveria ser considerada infundada, já que a proposição de princípios heurísticos é parte de qualquer disciplina em desenvolvimento. A fecundidade de PGSCp deve ser comprovada empiricamente. Como tentei mostrar, os estudos antropológicos de Richerson e Boyd e Harris já lhe dão certo apoio.

\section{AGRADECIMENTO}

Agradeço à Fundação de Amparo à Pesquisa do Estado de São Paulo (Fapesp) suporte e financiamento de meu projeto de pesquisa "Estratégias cognitivas e evolução humana" (processo n.2010/17862-7).

\section{NOTAS}

${ }^{1}$ Nesta e nas demais citações de textos publicados em outros idiomas, a tradução é livre.

${ }^{2}$ Existe certo desacordo sobre a possibilidade de considerar Richard Dawkins um sociobiologista. Não quero tomar aqui uma posição definitiva sobre essa questão, mas creio que, ao menos em relação aos dois pressupostos teóricos aqui esboçados, é evidente a proximidade entre o Dawkins do "gene egoísta" e a sociobiologia.

${ }^{3}$ Uma das principais diferenças entre o modelo de Cavalli-Sforza e Feldman e o de Boyd e Richerson é que, para os primeiros, a transmissão das habilidades culturais funciona lamarckianamente, enquanto, para os segundos, também a evolução cultural é darwiniana.

${ }^{4}$ Richerson e Boyd (2005) usam a expressão "mecanismos culturais adaptativos" para definir as características psicológicas que determinam a transmissão cultural. Uso o termo "adequado", em lugar de "adaptado" para referir-me ao comportamento individual em conformidade com esses mecanismos, com o fim de salientar a diferença entre os dois níveis de explicação aqui apresentados.

${ }^{5}$ Para identificar em detalhes esses problemas "propriamente sociais" seria preciso uma análise empírica. No entanto, é possível apresentar aqui brevemente, como exemplo, um fenômeno sem dúvida relevante: o progresso tecnológico. O contínuo avanço no processo de aperfeiçoamento de tecnologias, em muitos casos inúteis com relação à sobrevivência (como a televisão ou os telefones celulares), assim como a tendência 
a sua difusão massiva, dificilmente poderia ser explicado por um modelo sociobiológico ou psicologista, ou seja, referente a causas próximas. Esses fenômenos apresentam um desenvolvimento de problem solving altamente complexo, implicando a interação entre diferentes classes de comportamentos (teorização científica, implementação prática, difusão publicitária etc.), irredutíveis a ancestrais biológicos. Contudo, vários autores (Dawkins, summer 1993; Dennett, 1995) já observaram como essas dinâmicas respondem a certos padrões darwinianos de variabilidade, herdabilidade e adaptação, e podem influenciar os comportamentos de raiz mais marcadamente biológica, como a frequência da reprodução.

${ }^{6}$ A tentativa de caracterizar parâmetros adaptativos mais ou menos independentes do incremento da fitness biológica implica, necessariamente, um afastamento das posições adaptacionistas clássicas, já que, segundo elas, é justamente esse parâmetro que garante o caráter nomológico das várias explicações evolucionistas (Diez, Lorenzano, 2013). Cabe dizer que o escasso sucesso das epistemologias evolucionistas que aqui foram chamadas de clássicas (Popper, 1972; Toulmin, 1972) adveio, precisamente, do pouco cuidado na hora de definir a analogia entre seleção natural e progresso científico. Como nota Ruse (1986), não é suficiente individuar uns poucos elementos comuns aos dois processos para justificar a aplicação, in toto, do arsenal conceitual darwiniano à epistemologia. $\mathrm{O}$ afastamento das posições adaptacionistas não constitui, em si mesmo, um problema, mas é indispensável, para uma teoria evolucionista bem formada, definir os elementos que a diferenciam do darwinismo. $\mathrm{O}$ verdadeiro problema das epistemologias evolucionistas clássicas é o fato de que o desenvolvimento da ciência como aproximação à verdade (Popper, 1972, p.40) nada tem a ver com o conceito de adaptação biológica, e sim com o progressismo spenceriano, que é, muito provavelmente, uma teoria falsa.

${ }^{7}$ Por "nomológico" entende-se aqui, como de costume, a propriedade característica de uma explicação que "expressa uniformidades por meio de leis gerais" (Hempel, 2005, p.439).

${ }^{8}$ Não deixa de nos surpreender o fato de o mesmo Popper (1972, p.77), uns 15 anos depois de criticar o historicismo e certo "evolucionismo historicista" de tal maneira, afirmar: "Nos três níveis - adaptação genética, comportamento adaptativo e descoberta científica - o mecanismo de adaptação é fundamentalmente idêntico".

${ }^{9}$ Obviamente, Fodor e Piattelli-Palmarini não estão afirmando que o solo lamacento foi a única causa da derrota de Napoleão. O exemplo é relevante para a discussão porque nega a possibilidade de definir regularidades nomológicas a partir de eventos particulares, e não implica uma visão determinista da história humana.

${ }^{10}$ A morfogênese é um processo de desenvolvimento do organismo que determina importantes aspetos do crescimento e da diferenciação celular.

${ }^{11}$ Embora forneça neste estudo argumentos que pressupõem a existência de leis genuínas na biologia, por óbvias razões de espaço e pertinência não vou discutir aqui essa tese. Para uma análise detalhada, ver, por exemplo, Lorenzano (2011).

12 Nesse sentido, a citada tese de Huxley é, sem dúvida, enganosa.

${ }^{13}$ Relacionar um determinado comportamento à função que desenvolve na sociedade é matéria de um estudo empírico. Uma objeção comum aos modelos aqui tratados é a de que a escolha das categorias descritivas e dos comportamentos inclusos nela é arbitrária (Lewontin, 1979). Considero essa preocupação justificada, mas exagerada. É verdade que, sendo essas categorias a posteriori, empiricamente definidas a partir de uma pesquisa histórica, são provavelmente provisórias e, em certa medida, indeterminadas. Porém, isso acontece comumente nas ciências sociais e até na biologia, quando se trata de identificar o que define exatamente um determinado traço. Concluir que a escolha é "arbitrária" em qualquer caso nos parece, portanto, excessivo.

\section{REFERÊNCIAS}

BARAVALLE, Lorenzo.

A função adaptativa da transmissão cultural. Scientiae Studia, v.10, n.2, p.269-295. 2012a.

BARAVALLE, Lorenzo.

Extensión del dominio de la selección natural: enfoques sincrónicos y diacrónicos del cambio cultural. In: Congreso de la Sociedad de Lógica, Metodologia y Filosofía de la Ciencia en España, 7., 18-20 jul. 2012, Santiago de Compostela.
Actas... Santiago de Compostela: Servicio de Publicaciones de la Universidad de Santiago de Compostela. p.343-349. 2012b.

BARAVALLE, Lorenzo.

L'adattabilità delle superstizioni. Rivista di Estetica, v.48, n.1, p.253-270. 2011.

BLAKE, Judith.

Family size and achievement. Los Angeles:

University of California Press. 1989. 
BOYD, Robert; RICHERSON, Peter. Culture and the evolutionary process. Chicago: University of Chicago Press. 1985.

BRANDON, Robert N. Adaptation and evolutionary theory. Studies in history and philosophy of Science, part A, v.9, n.3, p.181-206. 1978.

CAVALLI-SFORZA, Luigi Luca. Geni, popoli e lingue. Milano: Adelphi. 1996.

CAVALLI-SFORZA, Luigi Luca; FELDMAN, Marcus.

Cultural transmision and evolution: a quantitative approach. Princeton: Princeton University Press. 1981.

DAWKINS, Richard.

Viruses of the mind. Free Inquiry, p.34-41.

Summer 1993.

DAWKINS, Richard.

The selfish gene. Oxford: Oxford University Press. 1976.

DENNETT, Daniel Clement.

Breaking the spell: religion as a natural

phenomenon. London: Penguin Books. 2006.

DENNETT, Daniel Clement.

Darwin's dangerous idea: evolution and the meanings of life. New York: Simon and Schuster. 1995.

DIEZ, José Antonio; LORENZANO, Pablo. Who got what wrong? Fodor \& Piattelli and Sober on Darwin: guide principles and explanatory models in natural selection. Erkenntnis, v.78, n.5, p.1143-1175. 2013.

DOBZHANSKY, Theodosius.

El azar y la creatividad en la evolución. In: Ayala, Francisco José; Dobzhansky, Theodosius (Ed.). Estudios sobre la filosofía de la biología. Barcelona: Ariel. p.392-430. 1983.

FODOR, Jerry; PIATTELLI-PALMARINI, Massimo. Gli errori di Darwin. Milano: Feltrinelli. 2010.

HARRIS, Marvin.

Good to eat: riddles of food and culture. New

York: Simon and Schuster. 1985.

HARRIS, Marvin.

El materialismo cultural. Madrid: Alianza Editorial. 1979.

HARRIS, Marvin.

Cannibals and kings: the origins of cultures. New York: Vintage. 1977.

HEMPEL, Carl Gustav.

La explicación científica. Barcelona: Paidós. 1.ed. 1965. 2005.

HUXLEY, Thomas Henry.

Lay sermons. New York: D. Appleton. 1880.
HULL, David.

Individuality and selection. Annual review of ecology and systematics. n.11, p.311-332. 1980.

KNAUFT, Bruce McNeill.

Good company and violence: sorcery and social action in a lowland New Guinea society.

Berkeley: University of California Press. 1985.

LEWONTIN, Richard Charles.

Sociobiology as an adaptationist program.

Behavioral science, v.24, n.1, p.5-14. 1979.

LORENZ, Konrad.

Behind the mirror: a search for a natural history of human knowledge. San Diego: Harcourt. 1974.

LORENZANO, Pablo.

Leis e teorias em biologia. In: Abrantes, Paulo César (Org.). Filosofia da biologia. Porto Alegre: Artmed. p.53-82. 2011.

MAYR, Ernst.

Storia del pensiero biológico: diversitá, evoluzione, ereditá. Torino: Bollati Boringhieri. 1982.

MAYR, Ernst.

Cause and effect in biology. Science, n.134, p.1501-1506. 1961.

MCBREARTY, Sally; BROOKS, Alison S.

The revolution that wasn't: a new interpretation of the origin of modern human behavior. Journal of human evolution, n.39, p.453-563. 2000.

NAGEL, Ernest.

The structure of science. New York: Harcourt. 1961.

NEEDHAM, John.

Science in traditional China: a comparative perspective. Hong Kong: The Chinese University Press. 1979.

PINKER, Steven.

How the mind works. New York: Norton. 1996.

POPPER, Karl.

Objective knowledge: an evolutionary approach.

Oxford: Oxford University Press. 1972.

POPPER, Karl.

The poverty of historicism. London: Routledge and Kegan Paul. 1957.

RICHERSON, Peter; BOYD, Robert.

Non di soli geni. Come la cultura ha trasformato l'evoluzione umana. Torino: Codice Edizioni. 2005.

RUSE, Michael.

Taking Darwin seriously: a naturalistic approach to philosophy. Oxford: Blackwell's. 1986.

SALAMON, Sonya.

Prairie patrimony: family, farming, and community in the Midwest. Chapel Hill: University of North Carolina Press. 1992. 
SOBER, Elliott.

Filosofia de la biología. Madrid: Alianza Editorial, 1.ed. 1993. 1996.

SOBER, Elliott; WILSON, David Sloan.

Unto others. Cambridge: Harvard University

Press. 1998.

STARK, Rodney.

For the glory of God: how monotheism led to reformations, science, witch-hunts, and the end of slavery. Princeton: Princeton University Press. 2003.

STERELNY, Kim; KITCHER, Philip.

The return of the gene. Journal of Philosophy, n.85, p.339-361. 1988.

TOOBY, John; COSMIDES, Leda (Ed.). The adapted mind: evolutionary psychology and the generation of culture. New York: Oxford University Press. p.19-139. 1992.
TOULMIN, Stephen.

Human understanding: the collective use and evolution of concepts. Princeton: Princeton University Press. 1972.

WILSON, David Sloan; SOBER, Elliott. Reintroducing group selection to the human behavioral sciences. Behavioral and Brain Sciences, n.17, p.585-654. 1994.

WILSON, Edward Osborn.

On human nature. Cambridge: Harvard University Press. 1978.

WILSON, Edward Osborn.

Sociobiology: the new synthesis. Cambridge:

Harvard University Press. 1975.

WYNNE-EDWARDS, Vero Copner. Animal dispersion in relation to social behaviour. Edinburgh: Oliver and Boyd. 1962. 